\title{
Ihr liebstes Titelbild 2017
}
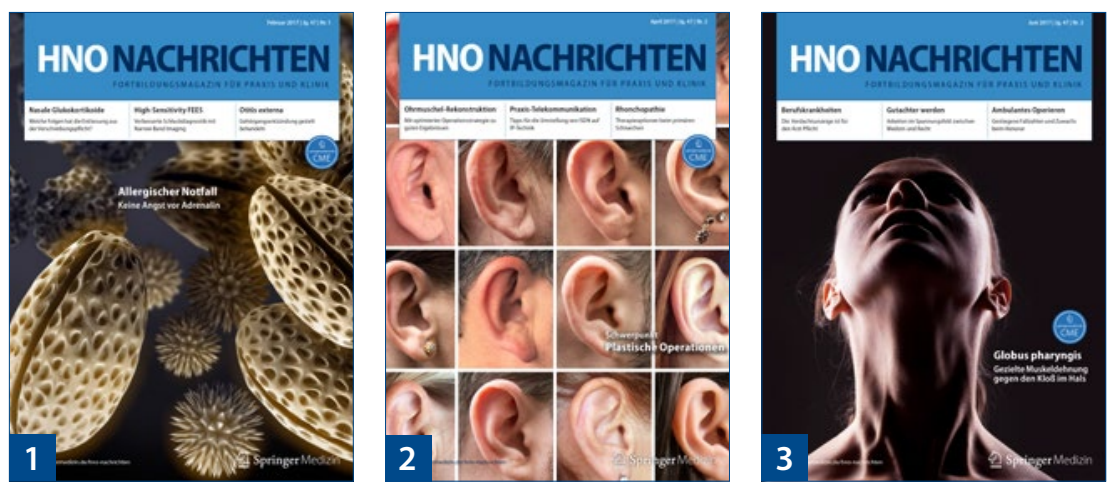

Das können Sie gewinnen

Unter allen Teilnehmern verlosen

wir folgende Preise:

1. Preis:

(im Wert von $120 €$ )

Lautsprecher der

Firma Bose

2. Preis:

(im Wert von $79 €$ )
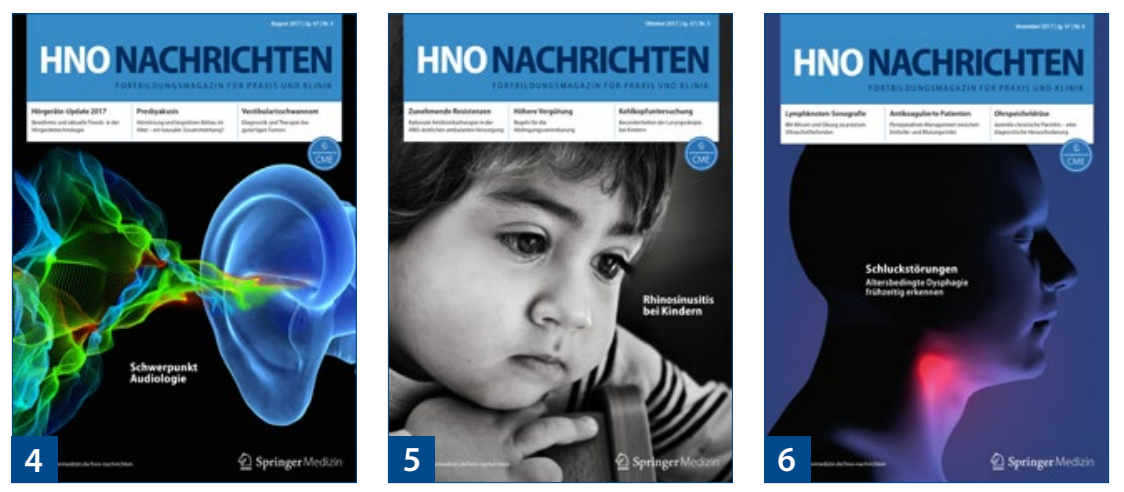

Objektive Audiometrie im Kindesalter Herausgeber: Hoth S, Mühler R, Neumann $\mathrm{K}$, Walger $\mathrm{M}$ Springer Verlag

3.-5. Preis: (im Wert von $20 €$ ) Welt-Adapter
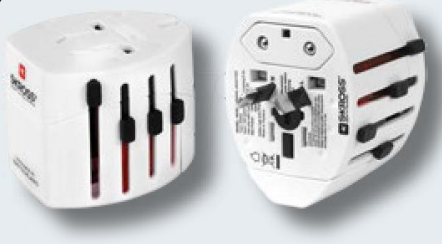

Teilnahme-Coupon bitte ausfüllen und bis 5. Feb. 2018 an die Redaktion faxen: Faxnr.: 089-20 3043 31450. Oder Sie senden uns Ihre Auswahl und Ihre Kontaktdaten per E-Mail an: doris.gebhardt@springer.com

Welches der abgebildeten Titelbilder der HNO Nachrichten gefällt Ihnen am besten?

Nr. $125,3 \quad 4 \quad 5 \quad 6$

Name

Vorname

Straße

Hausnummer

Postleitzahl

Ort

FAX: 089203043 31450Eine Barauszahlung der Preise ist nicht möglich. Der Rechtsweg ist ausgeschlossen. Mitarbeiter des Verlags dürfen nicht teilnehmen. 